\title{
HISPANISMO, INDIGENISMO Y AMERICANISMO \\ EN LA CONSTRUCCIÓN DE LA UNIDAD NACIONAL Y LOS DISCURSOS IDENTITARIOS DE BOLÍVAR, MARTÍ, SARMIENTO Y RODÓ
}

\author{
Mercedes Serna \\ Universidad de Barcelona
}

\begin{abstract}
Resumen: Domingo Faustino Sarmiento, José Martí y José Enrique Rodó dedicaron su vida a la construcción de la patria, como lo había hecho su mentor, Bolívar, y todos ellos vieron en la literatura y en el periodismo literario una forma de servicio a la nación. Sarmiento, Martí y Rodó fueron tocados asimismo por el regeneracionismo y el positivismo, o, si se quiere, en el caso de los dos primeros, por un romanticismo de acción, alejado del europeo. En el presente ensayo pretendemos analizar y contrastar las ideas que para la construcción de la nación fueron forjando Sarmiento, Martí y Rodó, sobre el hispanismo, el indigenismo y el americanismo, teniendo todos ellos, como modelo, el proyecto de Bolívar.
\end{abstract}

Palabras clave: positivismo, hispanismo, indigenismo, americanismo, nación.

Abstract: Domingo Faustino Sarmiento, José Martí and José Enrique Rodó devoted their lives to the construction of the patria, just as their mentor, Bolívar, had done before them. All of them saw literature and journalism as a way of serving their nation. Sarmiento, Martí and Rodó were influenced by regenerationism and positivism, or, in the case of the first two of these thinkers, by a romanticism based on action that was far removed from the European form of the movement. This study analyses and contrasts the ideas that Sarmiento, Martí and Rodó developed for the construction of the nation on Hispanicism, Indigenism and Americanism, all of which took Bolívar's project as their model.

Keywords: positivism, hispanicism, indigenism, americanism, nation.

\section{Introducción}

En los primeros años del XIX se inicia una nueva etapa para la mayoría de los pueblos hispanoamericanos que marca, con las guerras, el final de la colonia y el inicio de las naciones independientes. Con el intento de independencia 
política surge el problema de la independencia cultural o literaria. Entre los precedentes que habían conducido a la independencia pueden señalarse el malestar de los criollos, la expulsión de los jesuitas, las rebeliones iniciadas en el territorio peruano, el ejemplo de la independencia y la revolución estadounidense y francesa, respectivamente, o el contacto con la ideología de los enciclopedistas e iluministas.

Como señala Pedro Henríquez Ureña, la difusión de las nuevas ideas y la ilustración y educación del pueblo, en oposición a la cultura anticuada e imitativa que había prevalecido en tiempos coloniales, juntamente con la defensa de la libertad individual y la lucha por la abolición de todas las formas de esclavitud y servidumbre, se concebían como concomitantes naturales de la libertad nacional.

En 1810 se inician las guerras por la independencia de las colonias españolas. Las últimas batallas se libraron en 1825. Brasil se independizó en 1822. Cuba y Puerto Rico lo harían a finales de siglo. Muchos de sus líderes fueron hombres de educación filosófica y literaria.

El inicio de la independencia como un gran movimiento continental tuvo dos grandes libertadores: San Martín y Bolívar. Un precursor fue Francisco de Miranda, que murió un poco antes de que sus planes triunfasen. Se pensaba que la emancipación de España no acarrearía la ruptura del mundo hispánico en América, pero el proceso de degradación barrió y dio al traste con la utopía de Bolívar.

O. Paz reúne dos tendencias en el movimiento de Independencia: una, de origen europeo y liberal, que concibe a la América española como un todo unitario, como una asamblea de naciones libres, y otra, tradicional, que rompe lazos con la Metrópoli, sólo para acelerar el proceso de dispersión del Imperio.

Las relaciones entre independencia y literatura marcan también los inicios del siglo XIX y llegarán hasta el XX. No es tan solo el caso de Simón Bolívar, que no siendo literato, propiamente, dejó páginas de valor literario, sino el de José Martí, Domingo Faustino Sarmiento, José Enrique Rodó y tantos otros escritores que se sintieron, a la par, ideólogos y educadores.

El proyecto de Bolívar se puede definir como la búsqueda de la unidad americana, la creencia de que, más allá de los límites nacionales, existe una patria hispanoamericana. Esto tiene como consecuencia la importante actuación de destacadas figuras fuera de su lugar de origen, como el caso del maestro de Bolívar, Simón Rodríguez, del mismo Bolívar, de Andrés Bello o de Cecilio del Valle.

Simón Bolívar destaca por la interpretación que hizo de la realidad hispanoamericana y la anticipación de sus posibilidades de futuro y de unión. Su "Carta de Jamaica dirigida a un caballero que tomaba gran interés en la causa republicana en la América del Sur", de 1815, y su "Discurso en el Congreso de Angostura", de 1819, son piezas imprescindibles para estudiar este período. 
Arturo Ardao analiza la denominación de "Magna Colombia" y "Gran Colombia" en la "Carta de Jamaica", así como el supuesto positivismo de Bolívar. Ardao niega su positivismo y señala cómo Bolívar fue demócrata, término y concepto detestados por Comte. Bolívar admitía y enaltecía el Parlamento y fundaba su filosofía política en los principios de libertad, igualdad y soberanía del pueblo, y se apoyó en los escritos de Locke, Montesquieu, Voltaire, Rousseau o Bentham. Ardao analiza, asimismo, las doctrinas políticas de Bolívar y su pensamiento religioso. Leopoldo Zea, por el contrario, explica cómo el positivismo llevaría a su máxima expresión el proyecto ilustrado de Bolívar, positivismo que marcó los caminos de Sarmiento, Martí y Rodó. Estas contradicciones se producen por dos razones: la primera porque del positivismo cada uno de estos intelectuales tomó determinados aspectos, rechazando muchos otros; en segundo lugar, porque, a pesar de estar los tres ideólogos, políticos y reformadores unidos por la filosofía de Comte, a través o no de Bolívar, sus caminos fueron alejándose y tomando posiciones no sólo distintas, sino incluso enfrentadas.

De lo que no cabe duda es de la influencia de Bolívar en posteriores generaciones. Domingo Faustino Sarmiento, José Martí y José Enrique Rodó reconocieron que era el padre del pensamiento americano. En el presente ensayo, pretendemos analizar y contrastar las ideas que para la construcción de la nación fueron forjando Sarmiento, Martí y Rodó, sobre el hispanismo, el indigenismo y el americanismo, teniendo todos ellos, como referente, el proyecto de Bolívar. Sarmiento, Martí y Rodó dedicaron su vida a la construcción de la patria, como lo había hecho su mentor, Bolívar, y los tres vieron, como señala Henríquez Ureña, en la literatura y en el periodismo literario una forma de servicio público. Los tres creyeron en su destino romántico de salvadores de la patria, pero sólo como destino, pues fueron hombres de acción. Alejados del romanticismo ensoñador o nostálgico, Sarmiento, Martí y Rodó fueron tocados asimismo por el regeneracionismo y el positivismo, o, si se quiere, en el caso de los dos primeros, por un romanticismo de acción, alejado del europeo.

\section{Domingo Faustino Sarmiento}

Los jóvenes románticos vivieron la calamitosa situación de una Argentina que, tras la independencia, se debatía entre el antagonismo de las provincias y la capital (encarnado, respectivamente, en Córdoba y Buenos Aires), lo que llevaría al régimen "federal" de Juan Manuel Rosas. Los componentes de la "Asociación de Mayo" presentaron un conjunto de ideales orientados hacia la consecución de la libertad y el progreso, frente a la dictadura de Rosas que defendió los intereses rurales, despreciando toda influencia europea. Los más grandes opositores a dicho régimen fueron Esteban Echeverría, Juan María Gutiérrez, Juan Bautista Alberdi, Domingo Faustino Sarmiento o el chileno Victorino Lastarria.

El argentino Domingo Faustino Sarmiento (1811-1888) nació el 14 de febrero de 1811 en San Juan, Argentina. A los quince años comenzó a ejercer la 
enseñanza en su ciudad natal y posteriormente inició su carrera política como legislador provincial. Se exilió a Chile, en 1831, por su oposición a Rosas. Fue director de la Escuela Normal de Preceptoras en 1842 y viajó a Europa y Estados Unidos en 1849. Dedicó su vida a la carrera pública y política: se incorporó como corresponsal en la guerra contra Rosas, fue diputado, en 1860, en Santa Fe, gobernador de San Juan en 1862, ministro plenipotenciario en Chile, Perú y EE.UU. entre 1864 y 1868, Presidente de la República Argentina entre el 68 y el 74, y senador, ministro del interior y superintendente general de escuelas, entre 1875 y 1881 .

Sarmiento fue sin duda una personalidad controvertida, tanto por su carácter como por el contenido de sus escritos. Como ejemplo de lo primero, sólo cabe recordar que si por un lado fue retirado del gobierno, acusado de practicar los mismos vicios que reprochara a los caudillos gauchos, por el otro, durante su Presidencia, sentó las bases del desarrollo económico argentino, al estimular la enseñanza pública, el comercio, la agricultura y los transportes. Creó, asimismo, el primer observatorio astronómico de Sudamérica, en Córdoba. En cuanto a su producción, vale decir que Sarmiento imprime a todas sus obras una mirada histórica pues él se siente, sobre todo y más que "escritor", historiador, pero hay que señalar que dicha circunstancia histórica está ligada a una exaltación excesiva sobre su propia persona, que raya en la apología y la vanagloria. Desde el punto de vista del contenido, algunos de sus libros hoy en día no se divulgarían o serían de difícil publicación.

La obra que tradicionalmente más se ha destacado de la extensa producción sarmientina es la trilogía Civilización y barbarie, formada por Facundo, Vida de fray Félix Aldao y El Chacho, constituyendo la primera piedra fundamental del ensayo hispanoamericano. Pero para conocer las ideas de Sarmiento con respecto al indigenismo, el hispanismo y el americanismo es imprescindible tener en cuenta otras como Recuerdos de provincia y, sobre todo, la controvertida Conficto y armonías de las razas en América. Los temas fundamentales de todas ellas son los de la barbarie frente a la civilización, la raza, la herencia o la nación, si bien sus opiniones con respecto a dichos conceptos se irán radicalizando a lo largo de los años.

En Facundo (1845), en Recuerdos de provincia (1850) y en Conflicto y armonias de las razas en América (1883), el autor se propondrá analizar los males que padece la nación, sirviéndose para ello de la geografía y de la historia, y, en el caso de Conflicto, también de conceptos como raza o nación.

Si Sarmiento, en Facundo, acota la barbarie a Rosas y sus acólitos y cree que la solución radica en seguir el modelo europeo - francés o inglés, especialmente-, casi treinta años después, ya en sus postreros años, en Conflicto y armonias de las razas en América planteará la barbarie como una cuestión racial, considerando que el modelo a seguir son los Estados Unidos. Todos estos trabajos poseen, además, una impronta determinista. 
Conficto y armonías de las razas en América apareció en Buenos Aires, en 1883, y su segundo volumen se publicó, póstumamente ${ }^{1}$. En esta obra de carácter enciclopédico, Sarmiento reproduce muchas de las ideas que aparecían esbozadas en textos como Facundo o Civilización y Barbarie o en Argirópolis², de 1850, donde animaba a la sajonización de la patria: "Llamaos los Estados Unidos de la América del Sur y el sentimiento de la dignidad humana y una noble emulación conspirarán en no hacer un baldón del nombre a que se asocian ideas grandes" (Argirópolis, 1850).

En Conflicto, Sarmiento se propone escribir una nueva historia de América del Sur, tomando como modelos de referencia la Nueva historia de la conquista de México, de Robert Anderson Wilson, y la Historia de la conquista de México, de Prescott, ambos historiadores norteamericanos. Para ello, se propondrá estudiar, a través del método positivo, las condiciones físicas y morales de la raza española, de los indios y de los negros de la América hispana. Sarmiento se plantea que tiene que haber ciertos factores, más allá de los errores de los gobernantes o de ambiciones desenfrenadas, que hagan que toda la América española tome una misma dirección, como es el del conflicto de las razas.

Sarmiento elabora un inventario de razas para que el lector entienda los elementos que componen la sociedad que pretende analizar "y la influencia que hayan de ejercer estas castas en la nueva sociedad que ha de formarse" 3 . En la primera parte de su obra, analiza el cuerpo social que la colonización dejó, formado por la mezcla de dos razas de color con su propia estirpe, "en esta parte del continente únicamente descubierto". En un intento de dar validez científica a sus ideas, Sarmiento pretenderá realizar un estudio de indagación histórica, elaborando una clasificación etnológica de las razas en América. De esta manera, dividirá a las razas del continente en tres: la indígena, la negra y la mestiza o mezclada. La blanca "le merece" a Sarmiento un capítulo aparte. El estudio particular y pretendidamente racional de cada etnia (los quechuas, los guaraníes, la raza arauco-pampeana, las de color diverso, o las negras) no le sirve a Sarmiento más que para identificarlas de forma homogénea, sin rasgos distintivos, y calificarlas, indistintamente, como razas serviles e inferiores a la blanca. Sarmiento, en esta jerarquía, parece simpatizar más por la raza negra que por la india, por ser aquella más entusiasta, apta o predispuesta para el trabajo que ésta.

1 En el tomo segundo, Sarmiento dirá que Conflicto vio la luz en 1883.

2 En Argirópolis o La capital de los estados confederados del Rio de la Plata, de 1850, Sarmiento arremete contra la colonización española, negadora del progreso y propone para el gobierno de la nación, "atraer rápidamente la emigración europea (...), solicitarla, promoverla, alentarla, hasta que se establezca una corriente natural y espontánea (...)”.

3 F. D. Sarmiento, Obras completas. Conflicto y armonías de las razas en América, vols. 37 y 38, Buenos Aires, Universidad Nacional de la Matanza, 2001, I, 54.

4 Ibid., 44. 
Como señala David Solodkow ${ }^{5}$ el indio es para Sarmiento la peor de las razas como consecuencia de su propensión al ocio, lo que impide el progreso material, máximo objetivo sarmientino.

De este análisis, Sarmiento deducirá que la barbarie está formada en América por el indígena, el negro, el español y el mestizo que resulta de tan entrecruzadas razas.

Es decir que, según Sarmiento, la causa de la falta de progreso en Hispanoamérica se encuentra en la inferioridad racial de los pueblos que la habitan y se inicia con la inferioridad de los españoles, incapacitados para la democracia. El hereditario atraso tiene su origen, a su parecer, en la Inquisición, que fue la que arruinó a España. Por otra parte, Sarmiento criticará, incluso, los textos coloniales (crónicas de Indias, La Araucana o determinada poesía) por la visión idealista que han dado sobre la sociedad y el hombre indígenas, falseando la realidad.

Sarmiento señalará "que los que gobernamos hemos alcanzado un nivel de progreso" que no puede ser modificado "por la incorporación en ella (la sociedad) de razas inferiores"'. El argentino está absorbiendo un cuerpo extraño, una filosofía que, como señalaría José Martí en Nuestra América, nada tiene que ver con la naturaleza del pueblo americano. Sarmiento hace caso omiso de las características idiosincrásicas o culturales de la naturaleza americana, de la propia realidad, y procura implantar un método erróneo y una filosofía ajena, un injerto en cuerpo propio ${ }^{7}$.

Sarmiento es contundente en sus conclusiones: propone la sajonización de Hispanoamérica. Señala que la colonización del Norte de América se distingue de la del Sur en que los anglosajones no admitieron a las razas indígenas, "ni como socios, ni como siervos en su constitución social”. "¿En qué se distingue la colonización española?”, se pregunta retóricamente el autor, a lo que él mismo responde que "en que la hizo un monopolio de su propia raza, que no salía de la Edad Media al trasladarse a América y que absorbió en su sangre una raza prehistórica servil”9. ¿Qué le queda a esta América para seguir los destinos prósperos y libres de la otra?”, se vuelve a preguntar. "Nivelarse”, replicará, "por la nivelación del nivel intelectual y mientras tanto no admitir en el cuerpo electoral si no a los que se suponen capaces de desempeñar sus funciones". Y concluye: La América del Sur se queda atrás y perderá su misión providencial de sucursal de la civilización moderna. No detengamos a los Estados Unidos en su marcha;

5 D. Solodkow, "Racismo y nación: conflictos y (des)armonías identitarias en el proyecto nacional sarmientino", en Revista Decimonónica, Volumen 2, número 1, 2005.

6 Sarmiento, 2001, op. cit., 87.

7 Véase mi artículo "De Recuerdos de provincia a Conflicto y armonías de las razas en América: E1 retrato de Domingo Faustino Sarmiento y el destino de América”, en Revista Monteagudo, Murcia, 2011, en prensa.

8 Sarmiento, 2001, op. cit., II, 299.

9 Ibid. 
es lo que en definitiva proponen algunos. Alcancemos a los Estados Unidos. Seamos la América, como el mar es el Océano. Seamos los Estados Unidos ${ }^{10}$. El modelo a seguir, sin embargo, ya no será, ahora, la Europa del progreso, sino la Norteamérica de Horace Mann: "Ni la Francia ni la España tenían instituciones de gobierno que llevar a sus colonias, y han perecido los gajos de sí mismas que implantaron momentáneamente" 11 . Y concluye: "Lleguemos a enderezar las vías tortuosas en que la civilización europea vino a extraviarse en las soledades de esta América. Reconozcamos al árbol por sus frutos: son malos, amargos a veces, escasos siempre"12.

A pesar del marcado liberalismo que les caracteriza, Sarmiento y los intelectuales del 37 tienen una actitud conservadora por lo que respecta al nuevo orden. Del orden teológico al orden positivo, del militarismo al industrialismo, pretenderán formar una clase social y burguesa que haga por estas naciones lo que sus modelos han hecho en Europa y EE.UU. En Argentina surgirá una oligarquía apoyada en estas ideas liberales y positivistas, difundidas por la educación sarmientina y por una "determinada" inmigración formulada por los civilizadores. En realidad, la propuesta de Sarmiento reflejaba una dialéctica que tuvo una repercusión extraordinaria y que oponía — como la de "civilización y barbarie"-, los conceptos "latino y anglosajón". Para Sarmiento, esta oposición se planteaba, de manera determinista y categórica, en la elección entre la América hispana, monárquica, retrógrada, católica a ultranza, y en la que el peso del Estado es determinante y castrador, y la América anglosajona, demócrata, trabajadora, que velaba por la libertad de culto y que encumbraba al individuo sobre el Estado. $\mathrm{O}$, por el contrario, y recordando los célebres versos de Darío, otros apostaron por la América latina que sueña, ama, vibra y cree aún en Dios, frente a la América del Norte del progreso y del utilitarismo.

Esta oposición también se formuló bajo la visión de una Europa decadente, envuelta en continuas guerras intestinas, con sus milenarias monarquías - por naturaleza antidemocráticas, conservadoras y retardatarias-, y la América de los Estados Unidos, joven y democrática. Esta antinomia se reflejó en muchos intelectuales del siglo XIX, que tomaron partido por una u otra, como fue el caso de Tocqueville. José Martí buscará la manera de disolverla y con José Enrique Rodó se radicalizará.

\section{José Martí}

La postura de José Martí con respecto al americanismo, el indigenismo y el hispanismo es radicalmente distinta a la de Sarmiento, a pesar de que vivió en carne propia la colonización de su patria, Cuba, así como la cárcel, el presidio político o el exilio en los Estados Unidos. Nacido en La Habana, en 1853,

10 Ibid., 303.

11 Ibid., 301.

12 Ibid., 303. 
morirá en 1895, al iniciarse la guerra de independencia. La vida de Martí estuvo siempre vinculada a su vocación social y a su misión revolucionaria. En pro de la liberación de Cuba y de América Latina, sufrió deportaciones, malos tratos, encarcelamiento, presidio y separaciones desgarradoras: una vida ejemplar que llegó a su cenit en la guerra liberadora. Es, junto a Bolívar o San Martín, uno de los fundadores del pensamiento latinoamericano.

Como en Sarmiento, hay en Martí un sentimiento ambivalente hacia España y, como el argentino, criticó su retraso histórico. La hispanofilia de Martí surge cuando trata la España de Cervantes y del Siglo de Oro, de la República, de la nación liberal y progresista, de los comuneros, reflejándose esta simpatía no sólo en sus escritos periodísticos, sino a través de sus coplas o Versos sencillos. En los últimos años de su vida, fue endureciendo las críticas y los ataques contra la situación española, calificando el carácter de su política de "rudimentario y venal" y arremetiendo contra su ignorancia y sus hábitos despóticos.

Pero en el caso de Martí, es admirable la relación que mantuvo con España, si pensamos que, a pesar de ser condenado a cárcel, presidio y exilio por dicho país, propuso en sus crónicas, métodos y medidas para liberarla del atraso que padecía con relación a otros países europeos ${ }^{13}$. Como los krausistas españoles y los escritores de la Generación del 98, se ocupó de los males concretos que acuciaban a España - la apatía, la indiferencia, la ineficacia administrativa, los problemas agrarios- y del retraso en que se hallaba. Asimismo, puso de manifiesto la precaria situación de las capas bajas y no se olvidó de reconocer las virtudes espirituales del "sobrio y espiritual pueblo de España", virtudes que redescubrirían Neruda, Machado o Vallejo. En el campo literario, procedió de igual manera, criticando la subyugación de la literatura española del XIX a los modelos literarios foráneos.

Por ende, Martí, frente a Sarmiento, Alberdi y otros intelectuales, no buscó partir de cero, ni militó en el "parricidio", no quiso borrar a España o romper con ella, sino que asumió y reconoció el papel que dicho país tuvo en la construcción de los pueblos de América Latina. Como indica Enrique Krauze, en 1898, tras la guerra de Cuba, muchos escritores de la América española comenzaron a integrar otra "Generación del 98" formada por autores como José Enrique Rodó, Gabriela Mistral, Pedro Henríquez Ureña, José Vasconcelos o Alfonso Reyes. Todos ellos imaginaron la "utopía de América", la unión moral de los pueblos hermanos, "hijos todos de la Madre Patria y reconciliados con ella en los valores de la cultura y el idioma”. El punto de inflexión de esta nueva actitud lo hallamos en Martí quien, a pesar de que su misión era liberar a Cuba de sus colonizadores, siempre reconoció y apreció los valores de la cultura española, apartándose de las ideas positivistas de los argentinos Alberdi o Sarmiento y acercándose al pensamiento krausista y al trascendentalismo emersoniano.

13 J. Martí, Obras completas, La Habana, Editorial de Ciencias Sociales, 1975, XIV, 140. 
Martí militó en el indigenismo, en el hispanismo y en el americanismo. Frente a Sarmiento, fue de todos los "ismos" y de ninguno en concreto, es decir, se apartó del servilismo hacia una ideología o movimiento determinado.

Las raíces del indigenismo militante de Martí pueden hallarse en el siguiente discurso escrito para "E1 Progreso", de Guatemala, y fechado el 22 de abril de 1877, en el que arremete contra la conquista española:

Interrumpida por la conquista la obra natural y majestuosa de la civilización americana, se creó con el advenimiento de los europeos un pueblo extraño, no español, porque la savia nueva rechaza el cuerpo viejo; no indígena, porque se ha sufrido la ingerencia de una civilización devastadora, dos palabras que siendo un antagonismo, constituyen un proceso; se creó un pueblo mestizo en la forma, que con la reconquista de su libertad, desenvuelve y restaura su alma propia ${ }^{14}$.

En su "drama indio", escrito en Guatemala en 1877, Patria y libertad, Martí reivindica al indio frente al poder explotador de la Iglesia, el colonialista o el cacique:

Quebrantado/ su espíritu de hombre, ya no quedan/ al indio de los campos más que espaldas/para llevar las cargas de la Iglesia/ para pagar tributo a los caciques /para comprar al español sus telas/ con estas manos derribé maderos/ con estos miembros torturé la tierra/ con estos hombros, por barranca y llano/ más arrobas llevé que hojas la selva,/y más llanto lloré con estos ojos/ por mi eterna ignominia siempre nueva,/que ondas cruza la nave robadora/ que el fruto de mi mal a España lleva ${ }^{15}$.

En la voz de este indio resuenan las voces de los pueblos americanos, de Bolívar, y de la epopeya de libertad que años más tarde poetizará Neruda en su Canto General.

En La Edad de Oro ${ }^{16}$, cuyo primer número salió en julio de 1889, su militancia indigenista se nos revela, igualmente, en los “Tres Héroes", en su oración

14 Ibid., VII, 98.

15 Ibid., XVIII, 136.

16 Léase como ejemplo de todo este sentido americanista que pretende dar a las letras hispanoamericanas su revista $L a$ Edad de Oro, 1889, que solo vio cuatro números. Escrita especialmente para niños de América, la función era entretenerles, educarles y enseñarles la historia pasada y la contemporánea. La actividad pedagógica y educativa, la búsqueda de la regeneración del hombre, el hacerse a uno mismo y otros conceptos humanistas en parte derivados de la filosofia krausista, constituyen el ideario de la revista. Está compuesta de artículos científicos y literarios, cuentos, descripciones de juegos y costumbres, viajes, biografias, poesías, crónicas y estudios sobre el origen del mundo, sus razas y modos de vida. La misión profundamente americana de esta revista la explica Martí en una carta dirigida a su amigo Manuel Mercado: "ayudar, con ella, a llenar nuestras tierras de hombres originales, criados para ser felices en la tierra que viven, y vivir conforme a ella, sin divorciarse de ella, ni vivir infecundamente en ella". 
sobre Bolívar, de 1893, en "Las ruinas indias", o en "E1 Padre Las Casas". Sin embargo, tampoco debemos confundir indigenismo con inmovilismo. Martí busca la conjunción, de difícil consecución, entre indigenismo y universalismo, tal como veremos en su ensayo Nuestra América.

Cintio Vitier estudia el indigenismo de Martí aclarando que nada tiene que ver con un romanticismo nostálgico, idealista y paralizador. Martí, verdadero romántico, desdeña cualquier cerrazón de pensamiento o actitud nostálgica. En una carta a Joaquín Macal, señala: "la vida — reflexiona el cubano— debe ser diaria, movible, útil; y el primer deber de un hombre de estos días, es ser un hombre de su tiempo". A Martí no se le escapa el mundo y quiere que América ingrese en el progreso. En el prospecto de la Revista Guatemalteca que quiso publicar, pero que nunca vio la luz, proponía:

Nosotros hemos de entrar en esa gran corriente de inventos útiles, de enérgicos libros, de amenas publicaciones, de aparatos industriales, que el mundo viejo, y el septentrión del nuevo, arrojan de su seno, donde hierven la actividad de tantos hombres, la elocuencia de tantos sabios, la vivacidad de tantas obras ${ }^{17}$.

El indigenismo, el americanismo, el peligro que suponían los Estados Unidos y la conciencia de la nueva expresión americana son temas que trató también Martí en el prólogo a El poema del Niágara, de Juan Antonio Pérez Bonalde, en su místico poemario Ismaelillo, en el artículo titulado el Carácter de la Revista Venezolana y en muchos otros de su revista La Edad de Oro. Pero las ideas de Martí se encarnan, fundamentalmente, en sus crónicas periodísticas, género que le consagrará como uno de los mejores prosistas en lengua española de su tiempo. Es a partir de 1882 cuando las crónicas de Martí adquieren reconocimiento por América. Gracias a las crónicas martianas, comenta Julio Ramos ${ }^{18}$, el ensayo comienza a erigirse como un modo alternativo y privilegiado para hablar sobre política. La literatura se postula como la única hermenéutica capaz de resolver los enigmas de la identidad latinoamericana. Las crónicas sirvieron como discurso para que el lector reflexionase sobre Hispanoamérica como totalidad. Martí ahonda, en sus crónicas, en el antiimperialismo y el anticolonialismo y señala las cualidades de lo que él denomina "Nuestra América". A través del periodismo, Martí, de igual manera, alertó a los pueblos americanos de los posibles peligros históricos.

Es en las crónicas donde se manifiesta el profundo americanismo de Martí y, en concreto, en Nuestra América, donde profundizará en la línea bolivariana. Son famosas las palabras del discurso que pronunció en la velada de la Sociedad Literaria Hispanoamericana, el 28 de octubre de 1893, sobre Bolívar, y publicadas

17 Martí, 1975, op. cit., VII, 104.

$18 \mathrm{~J}$. Ramos, Desencuentros de la modernidad en América Latina. Literatura y política en el siglo XIX, México, FCE, Tierra Firme, 1989, 16. 
en "Patria", Nueva York, el 4 de noviembre de 1893: "Ni de Rousseau ni de Washington viene nuestra América, sino de sí misma”. Mientras Sarmiento, imbuido del pensamiento positivista, reconocía, implícitamente, la inferioridad de América Latina frente a los EEUU, Martí señalará las virtudes autóctonas de lo que él denomina "Nuestra América". Martí disolverá, por fin, la falsa antinomia civilización-barbarie en la que tantos reformistas o ideólogos incurrieron.

Martí como ideólogo recoge el legado de Bolívar, a quien rinde ardientes homenajes en diversas ocasiones, busca el rescate de lo autóctono, de lo indígena, e insiste en la amenaza norteamericana. En un discurso leído en Caracas, el 21 de marzo de 1881, a través de la alegoría, avisaba Martí:

Hay que devolver al concierto humano interrumpido la voz americana, que se heló en hora triste en la garganta de Netzahualcóyotl y Chilam; hay que deshelar, con el calor de amor, montañas de hombres; hay que detener, con súbito erguimiento, colosales codicias ${ }^{19}$.

En Nuestra América avisa, fundamentalmente, de dos peligros: el aldeanismo y el imperialismo norteamericano. Frente al primero, Martí hace una llamada al cultivo del hombre. La ignorancia hace esclavos a los hombres y a los pueblos pasto de las dictaduras y de la colonización. Martí, krausista, busca armar intelectualmente a su pueblo. Por otro lado, teme el desarraigo, el extranjerismo, como consecuencia del sentimiento de inferioridad que arrastra un pueblo que pertenece a razas no europeas (india, negra, mestiza). Distingue entre el criollo exótico, que identifica lo extranjero con la civilización y lo nativo con la barbarie, (Sarmiento es buen ejemplo), y el mestizo autóctono que cree, como él mismo, que en lo nativo está la raíz de la civilización. Arremetiendo contra Sarmiento, Martí aclarará que no hay batalla entre civilización y barbarie, sino entre la falsa erudición y la naturaleza" 20 .

Como Rousseau, piensa que el hombre nativo, no contaminado, es bueno por instinto y busca la asimilación de todo aquello que confirme la propia originalidad. Convencido de que el mal está en la ignorancia, promueve el conocimiento de la historia y de la cultura universal. No duda, como tantas veces señalará Carlos Fuentes, de que América Latina nace de una violación, híbrida y mestiza, es decir, catolicismo español prepotente y feudal y mestizaje de blanco, indio y africano esclavo. La hibridez americana, la colonización cultural, la soledad de este laberinto americano las expresa Martí extraordinariamente bien en estas palabras: "Éramos una visión, con el pecho de atleta, las manos de petimetre y la frente de niño. Éramos una máscara, con los calzones de Inglaterra, el chaleco parisiense, el chaquetón de Norteamérica y la montera de España”21.

19 Martí, 1975, op. cit., VII, 285.

20 Ensayos y crónicas, edición de J. O. Jiménez, Madrid, Cátedra, 2004, 160.

21 Ibid., 164. 
Y, seguidamente, ofrece soluciones:

El genio hubiera estado en hermanar, con la caridad del corazón y con el atrevimiento de los fundadores, la vincha y la toga: en desestancar al indio; en ir haciendo lado al negro suficiente; en ajustar la libertad al cuerpo de los que se alzaron y vencieron por ella ${ }^{22}$.

La propuesta de Martí es clara: ni aldeanismo, ni desarraigo, ni colonialismo cultural; tomar lo mejor de cada nación, sean los Estados Unidos, sea España; no comulgar ni con el romanticismo exaltador indigenista, ni con la admiración incondicional por el progreso norteamericano, y, por último, amar lo propio.

\section{José Enrique Rodó}

El escritor uruguayo José Enrique Rodó (1871-1917) se sitúa, como Martí, entre las postrimerías del romanticismo, el naturalismo literario, el positivismo filosófico y el espiritualismo. Pensador, crítico y ensayista, fue autodidacta y su obra recorre los ámbitos periodístico, político y literario. Sus crónicas periodísticas, como las de Martí, recorrieron toda América. Fundó la Revista nacional de literatura y ciencias sociales, colaboró en el periódico El orden y fue redactor en el Diario del Plata y en El telégrafo. Como para el resto de estos ensayistas, para Rodó la crítica fue vehículo formador del hombre. Perteneciente a la denominada Generación del 900, creyó, como muchos otros de sus componentes, que las guerras de independencia habían fracasado.

En Rodó puede notarse el influjo bolivariano en El Mirador de Próspero, exposición de su americanismo político: "La unidad política que consagre y encarne esa unidad moral — el sueño de Bolívar- es aún un sueño, cuya realidad no verán quizás las generaciones hoy vivas”23.

Unidad política que resulta de la concepción de América como una grande y única patria. Rodó conoció de cerca la actividad política de Martí, sus dotes visionarias, su lucha patriótica, sus preferencias filosóficas y la búsqueda de una nueva literatura, a través de un nuevo lenguaje. El escritor uruguayo sigue la línea martiana por lo que respecta a cuatro pilares filosóficos, literarios e ideológicos: el positivismo, el krausismo, el modernismo y el americanismo.

Frente a Sarmiento, Rodó — como Martí- fue liberándose del positivismo porque éste ofrecía una visión excesivamente pragmática y cartesiana de la realidad y además, en cuestiones políticas, se acercaba a un régimen autoritario. Rodó, como Martí, reconoció, no obstante, en Rumbos nuevos, la importancia que la filosofía positivista tuvo en generaciones posteriores, es decir, que aceptó su deuda con el positivismo:

22 Ibid.

23 J. E. Rodó, El Mirador de Próspero, Barcelona, Ed. Cervantes, 1928, 170. 
La iniciación positivista dejó en nosotros, para lo especulativo como para lo de la práctica y la acción, su potente sentido de la relatividad; la justa consideración de las realidades terrenas; la vigilancia e insistencia del espíritu crítico; la desconfianza para las afirmaciones absolutas; el respeto de las condiciones de tiempo y de lugar; la cuidadosa adaptación de los medios a los fines; el reconocimiento del valor del hecho mínimo y del esfuerzo lento y paciente en cualquier género de obra; el desdén de la intención ilusa, del arrebato estéril, de la vana anticipación. Somos los neoidealistas, o procuramos $\operatorname{ser}^{24}$.

La renovación de la forma y de la idea es característica esencial del modernismo y dicha renovación sólo podía entenderse en el sentido de progreso, progreso que el positivismo europeo se encargó de fomentar. Así, a pesar de que el modernismo no podía comulgar con un arte industrializado, burgués, mediatizado por el poder económico, realista y naturalista, útil y práctico, de dicha filosofía tomó más rasgos de los que se han observado.

El neoidealismo en el que el Rodó se integra parte del romanticismo pulido por el positivismo. Los modernistas heredarían del positivismo, a pesar de nacer como un movimiento enfrentado a dicha filosofía, la formación de un espíritu crítico, la relatividad de juicios, la desmitificación de la religión, la lucha contra el integrismo religioso, la secularización y el afán de progreso.

Rodó, uno de los ensayistas y pensadores más fecundos de América Latina, fue de los primeros en vislumbrar asimismo las relaciones entre positivismo y modernismo. Rodó vio la capacidad innovadora del modernismo concibiéndolo como superación de corrientes anteriores. No enfrentó positivismo a modernismo sino que entendió dicha filosofía como paso previo para llegar a "concepciones más altas”. Y es que Rodó, como Martí o Juan Ramón Jiménez, asimilaron el modernismo como un movimiento no sólo poético o literario sino ideológico, reformista y trascendente. Además, hay que pensar que tanto Martí como Rodó se guiaron por principios krausistas y el krausismo espiritualista y el positivismo materialista coinciden, como Hegel — del que Krause fue epígono- y Comte. La segunda época del krausismo intentó asimilar el positivismo, denominándose época del krauso-positivismo. Martí y Rodó fueron krauso-positivistas, uno y otro lucharon por la regeneración espiritual y moral de la patria a través de reformas educativas, al igual que Sarmiento, si bien a éste le faltó el componente espiritual y trascendental.

La huella krausista se manifiesta en Martí y Rodó. Uno y otro se acercaron a los presupuestos estéticos, éticos y pedagógicos krausistas que pueden resumirse en sus teorías sobre la literatura y en la idea que tienen del hombre como síntesis de las esencias divinas. Este principio ético se apoya en el trabajo de la propia personalidad. Los partidarios del krausismo son moralistas empeñados en reformar al hombre y a la sociedad: formar hombres útiles al servicio de la

24 J. E. Rodó, Obras completas, Montevideo, Barreiro y Ramos, 1956, 4, 37. 
humanidad, crear hombres genuinos, enteros, educándolos "en aptitud de tomar por sí lo útil, sin ofuscarlos", no desfigurando su naturaleza, para así conseguir poblar la tierra de una generación vigorosa y creadora.

Las obras de Rodó, Martí y Sarmiento son de carácter pedagógico y reformista porque sus autores demuestran la confianza que depositaron en la juventud americana y a ella se dirigen, muy especialmente. El ideal educativo krausista, que busca incorporar a la juventud a la vida pública para transformarla y darle un nuevo sentido moral, se despliega, concretamente, en la revista La Edad de Oro, de Martí, y en Ariel, de Rodó.

Ariel pretende orientar y alentar a la juventud a dar un nuevo sentido moral a una sociedad que, habiendo perdido el rumbo, se desliza vertiginosamente hacia su decadencia. Rodó arremeterá, en su preocupación por el progreso cultural de Hispanoamérica, contra el decadentismo francés y contra el modernismo epidérmico. El decadentismo, para el uruguayo, contraviene un proyecto previo de americanismo literario. Martí criticó no sólo el decadentismo, sino las escuelas realista y naturalista porque no ayudan a elevar, ni a mejorar, ni a regenerar los espíritus hambrientos.

Es posible que la preocupación americanista de Martí y Rodó les llevara a asumir planteamientos krausistas. El americanismo es militancia y misión. Señala Rodó al respecto:

Es Proteo el libro en que pienso haber puesto lo más intenso y acabado de mi labor hasta el presente. Con más amplio horizonte y más reposo que en Ariel, tiendo la mirada por parecidos campos de meditación y de prédica, aunque concretándome especialmente esta vez a la cultura del propio yo, a la formación de la personalidad, honda y firmemente desenvuelta mediante una incesante y orgánica renovación. Predico la acción, la esperanza y el amor a la vida porque creo que tal es el rumbo por donde haremos obra de espíritu realmente americano, obra de porvenir ${ }^{25}$.

Ariel, inspirado en el pensamiento de los ideólogos Renan y Guyau, influyó en el surgimiento del americanismo genuino. La unidad espiritual de América con la que había soñado Bolívar es la que persiguieron Martí, Darío y Rodó. El americanismo y el antiimperialismo son temas también constantes en la obra del uruguayo. Siguiendo su pensamiento, el hombre debe desarrollar su espíritu por medio de una estética individual. La democracia norteamericana tiene como base el espíritu utilitario, calificado por Rodó de "plutocracia". Frente a esta teoría, se alza la América Latina, como idea unitaria, que tiene como modelo a Bolívar.

Rodó trasladará la teoría de los héroes de Carlyle, al trazar cuatro estudios sobre héroes del pasado —Bolívar, Martí, Artigas y Montalvo—, en su pretensión

25 Ibid., 6, 1401. 
de sacar a la luz el heroísmo de las épocas pasadas para construir la América futura. Rodó parte de la necesidad que tiene América de lo heroico para cumplir con su programa regeneracionista.

Como los positivistas en general, el montevideano admite el influjo norteamericano. A pesar de la "nordomanía", entiende que el cosmopolitismo debe acatarse como "una irresistible necesidad de nuestra formación". Ello, sin embargo, no excluye "ni ese sentimiento de fidelidad a lo pasado, ni la fuerza directriz y plasmante con que debe el genio de la raza imponerse en la refundición de los elementos que constituirán al americano definitivo del futuro"26.

Reconoce su admiración por la cultura y el hombre norteamericanos, si bien rechaza su mal gusto, su falta de instinto poético ancestral, el egoísmo del bienestar personal y colectivo, su "semicultura" universal y una "profunda languidez de la alta cultura", males debidos a la democratización de la educación. Todo ello ha creado un ambiente de mediocridad del que, en su opinión, no surgirá jamás ni el heroísmo, ni la santidad. Les reprocha a los norteamericanos el exclusivo cuidado del engrandecimiento material. En su opinión, carecen de la vida del espíritu.

"Ariel" significa "idealidad y orden en la vida, noble inspiración en el pensamiento, desinterés en moral, buen gusto en arte, heroísmo en la acción, delicadeza en las costumbres" ${ }^{27}$. Es, en suma, la representación de los valores que debe tener el hombre superior. Rodó pretende, asimismo, que los jóvenes, de quienes dependerá el futuro de América Latina, no se dejen arrastrar por el materialismo del fin de siglo. Aconseja la educación integral del ser - siguiendo el modelo griego antiguo-, del espíritu y el cuerpo. Busca, como hiciera Martí, la conjunción entre los valores materiales y espirituales, entre el idealismo y el progreso, entre lo bello y lo útil. Rodó aprueba las relaciones entre los bienes positivos y los bienes intelectuales y morales, porque de las ventajas materiales se obtienen elementos de superioridad espiritual. Esa voluntad sintetizadora aparece igualmente en Martí, en quien se puede advertir la defensa del realismo, del positivismo, del esteticismo, del parnasianismo, del krausismo, del naturalismo e incluso del materialismo, siempre que todos ellos se manifiesten en su justo medio.

Rodó, como Darío, no vio con buenos ojos el poder de Norteamérica. En Ariel, Rodó teme la desnaturalización de América y parece enfrentarse a la admiración que los positivistas, como Sarmiento, profesaron por los Estados Unidos. Ya Martí fue uno de los primeros, si no el primero, que vislumbró el peligro que suponía el imperialismo norteamericano para América Latina y de ello avisó, reiteradamente, en sus crónicas periodísticas. Ya desde sus primeros opúsculos, El presidio político en Cuba (1871) o La República española ante la

27 Ibid., 68. 
revolución cubana (1873) se declaró antiimperialista y se impuso como misión primera la libertad de su Isla.

Pero si bien Sarmiento, Martí y Rodó son reformistas empeñados en trabajar por el futuro de América, sus ideas en torno al americanismo, el indigenismo y el hispanismo, como hemos analizado, son divergentes. Martí y Rodó reconocieron, frente a Sarmiento, el legado histórico de España en la formación de "Nuestra América", y en sus obras encarnaron el hispanismo y la latinidad, si bien en el cubano no se produjo la dicotomía profunda e insalvable "del arielismo contra el calibanismo" de Rodó, - léanse sus "Escenas Norteamericanas"-, de la misma manera que nunca enfrentó hispanismo y americanismo. Con respecto al americanismo, Sarmiento desprecia lo propio y proclama la subordinación a los EE.UU. En Rodó, "el americanismo es una faceta más de su personalidad" 28 . El escritor uruguayo luchó por encontrar salida entre un pasado americano, que consideraba inferior o devaluado, y el suministro de ideas europeas que le llegaban de fuera (Renan, Tolstoi, Carlyle, Guyau o Taine). La exploración del pasado, tan del gusto de Rodó, no es tan intensa en Martí, ni es fruto de una "ideología del exilio" o el medio para alejarse o evadirse del presente. Martí tampoco pretendió ignorar las ventajas de asomar los ojos a civilizaciones más avanzadas y aprender de ellas. La originalidad no es incompatible con la universalidad. Frente a Rodó, Martí busca la apertura hacia otras literaturas, pero no para imitarlas, sino para eliminar la lacra de la subordinación e independizarse de la literatura española.

\section{BIBLIOGRAFÍA}

Alsina, V., "Notas a civilización y barbarie", edición de Facundo, Caracas, Ayacucho, 1977.

Andino, A., "Bolívar, Olmedo y el Canto a Junín, Cuadernos Hispanoamericanos, 279, 1973.

Ardao, A., "El americanismo de Rodó", en Estudios latinoamericanos de historia de las ideas, Caracas, Monte Ávila editores, 1978.

Balaunde, V. A., Bolivar y el pensamiento político de la revolución hispanoamericana, Madrid, Cultura Hispánica, 1959.

Blanco Fombona, R., El pensamiento vivo de Bolivar, Buenos Aires, Losada, 1958.

Caballero Wangǘmert, M., Introducción a "Recuerdos de provincia" de Domingo Faustino Sarmiento, edición digital, Alicante, Biblioteca Virtual Miguel de Cervantes, 2010.

Castro, B., José Enrique Rodó modernista. Utopía y regeneración, Tenerife, Universidad de la Laguna, 1990.

Comte, A., Discurs sobre l' esperit positiu, traducció de Jaume Melendres, edició a cura de Joan Rovira, Barcelona, 1982.

Fernández, T., Los géneros ensayísticos hispanoamericanos, Madrid, Taurus, 1990.

28 A. Ardao, "El americanismo de Rodó", en Estudios latinoamericanos de historia de las ideas, Caracas, Monte Ávila editores, 1978, 25, 112. 
Fernández Retamar, R., Fervor de la Argentina. Antología personal, Buenos Aires, Ediciones del Sol, 1993.

González, A., La crónica modernista hispanoamericana, Madrid, Porrúa Turanzas, 1983.

Gutiérrez Girardot, R., Modernismo. Supuestos históricos y culturales, México, FCE, 1988.

Halperin Donghi, T., "Prólogo” a D. F. Sarmiento, Campaña en el ejército grande aliado de Sud América, México, FCE, 1958.

Henríquez Ureña, P., Historia de la cultura en la América Hispana, México, FCE, 1947.

-, "La obra de José Enrique Rodó", en Conferencia del Ateneo de la Juventud, México, UNAM, 1962.

- Historia cultural y literaria de la América hispánica, edición de Vicente Cervera, Madrid, Verbum, 2007.

Martí, J., Obras completas, La Habana, Editorial de Ciencias Sociales, 1975.

—, Ensayos y crónicas, edición de J. O. Jiménez, Madrid, Cátedra, 2004.

Moraña, M., "José Enrique Rodó”, en Historia de la literatura hispanoamericana, vol. II, Madrid, Cátedra, 1987.

Outram, D., The Enlightenment. Cambridge, University Press, 1995.

PAz, O., El laberinto de la soledad, México, FCE, 1982.

Ramos, J., Desencuentros de la modernidad en América Latina. Literatura y politica en el siglo XIX, México, FCE, Tierra Firme, 1989.

Rodó, J. E., El Mirador de Próspero, Barcelona, Ed. Cervantes, 1928.

-, Obras completas, Montevideo, Barreiro y Ramos, 1956.

-, Antología del pensamiento político, social y económico de América Latina, edición de J. L. Abellán, Madrid, Ediciones de Cultura Hispánica, 1991.

Sarmiento, D. F., Obras completas. Conflicto y armonías de las razas en América, vols. 37 y 38, Buenos Aires, Universidad Nacional de la Matanza, 2001.

-, Recuerdos de provincia, prólogo de S. Zanetti y M. B. Pontieri, Barcelona, Biblioteca Argentina, Editorial Sol, 2001 ${ }^{\mathrm{a}}$.

Sarlo, B. y C. Altamirano, Ensayos argentinos. De Sarmiento a la vanguardia, 1983.

Serna Arnaiz, M., "Algunas dilucidaciones sobre el krausismo en Martí", Cuadernos bispanoamericanos, 521, 1993, 137-145.

—, "José Martí y José Enrique Rodó: un acercamiento ideológico", Anuari de Filología, XVII, núm. 5, 1994, 115-126.

-, "De Recuerdos de provincia a Conflicto y armonías de las razas en América: El retrato de Domingo Faustino Sarmiento y el destino de América”, Revista Montevideo, número próximo a salir, 2011.

Solodkow, D., "Racismo y nación: conflictos y (des)armonías identitarias en el proyecto nacional sarmientino”, en Revista Decimonónica, Volumen 2, número 1, 2005.

Schulman, I. A., ed., Nuevos asedios al modernismo, Madrid, Taurus, 1974.

ZEA, L., El pensamiento latinoamericano, edición a cargo de L. Jiménez Ramírez, 2003.

—, compilación, prólogo y cronología al Pensamiento positivista latinoamericano, Caracas, Biblioteca Ayacucho, 1980. 
